American Journal of Applied Sciences 5 (3): 221-226, 2008

ISSN 1546-9239

(C) 2008 Science Publications

\title{
Stochastic Inflow Simulation for Searching Rule Curves
}

\author{
Anongrit Kangrang, Anujit Phumphan and Witsanukorn Chaiyapoom \\ Faculty of Engineering, Mahasarakham University, Khamriang Campus \\ Kantharawichai, Mahasarakham, 44150, Thailand
}

\begin{abstract}
Rule curves are basic monthly guidelines for long term reservoir operation. Generally, the optimal rule curves are searched by reservoir simulation model and optimization techniques. A traditional reservoir simulation does not consider the risk of reservoir operation caused by natural uncertainty from inflow. A stochastic simulation model embedded genetic algorithm model is developed for searching the optimal rule curves in this study. Synthetic inflows are used in the developed model for assessing the risk reservoir operation. Single and multi-reservoir systems are applied to assess the efficiency of the proposed technique. The developed model has been applied to determine the optimal rule curves of the Bhumibol and Sirikit Reservoirs (the Chao Phraya River Basin, Thailand) for multi-reservoir system and the Ubolratana Reservoir (the Chi River Basin, Thailand) for single system. The optimal rule curves of each system were used to assess by a Monte Carlo simulation. The results show that the situations of water shortage and excess release of the obtained rule curves are not significantly different from the situation of the curves searching by tradition simulation. It can be concluded that the stochastic simulation model embedded genetic algorithm provided the optimal rule curves as considering the risk of reservoir operation. Furthermore, the proposed model is applicable for both single and multi-reservoir systems.
\end{abstract}

Keywords: Reservoir operation, rule curves, genetic algorithms, stochastic model

\section{INTRODUCTION}

Nowadays an integrated water resources management is addressed in the possible practice and high efficiency. There are two main parts of management; demand management and supply management. The section of supply management is a reservoir operation. A reservoir simulation model is a modeling technique that is used to analyze the behavior of a system on the computer for operating the reservoir. Rule curves are fundamental guidelines for long term reservoir operation. Normally, rule curves are searched by reservoir simulation model and optimization techniques. In the past decade, the rule curves are obtained by using several sets of trial rule curves to test in reservoir simulation model ${ }^{[1]}$. This method is straightforward and applicable for both simple and complex systems. The monthly input data of reservoir simulation include historic inflows, evaporation, rainfall, infiltration, physical characteristic of the reservoir and conditional rule curves ${ }^{[2,3]}$. However, the reservoir simulation method does not guarantee to yield the optimal rule curves because of arbitrary engineer.

A dynamic programming (DP) is another optimization technique applied to search the non-linear problems of water resource ${ }^{[4,5,6]}$. Unfortunately, the application of DP to multi-reservoir system is limited due to a course of dimensionality. To overcome this problem Chleeraktrakoon and Kangrang ${ }^{[7]}$ applied the DP with a principle progressive optimality (DP-PPO) to determine the optimal rule curves. The input data of this technique are the same as those using in the previous reservoir simulation model.

Recently, genetic algorithms (GAs) embedded the reservoir simulation model has been applied to search the rule curves of the reservoir system ${ }^{[8,9,10,11]}$. The best part of GAs is that they can handle any type of objective function. Furthermore, the proposed model can handle any condition of reservoir simulation such as initial reservoir capacity and the period of inflow record. The accepted objective functions are a shortage index, frequency of water shortage, average water shortage and magnitude of water deficit. However, the appropriate objective function for searching the curves is average water shortage. Also, a smoothing function constraint is required to include into the proposed GAs for fitting the rule curves ${ }^{[12]}$.

The reservoir simulation models which mentioned above require the same necessary input data including
Corresponding Author:
Anongrit Kangrang, Faculty of Engineering, Mahasarakham University, Khamriang Campus, Kantharawichai, Mahasarakham, 44150, Thailand 
inflow record, physical characteristic of the reservoir and conditional rule curves ${ }^{[2,3,13]}$. Moreover, all simulation models require long period of dry historic inflows ${ }^{[7,14,15]}$. This is the limitation to some systems that are lack of sufficiently long inflow record. However, this reservoir simulation is incapable of risk analyze of reservoir operation caused by natural uncertainty inflow. The reservoir operation risk is adopted for flood control and hydropower ${ }^{[2,16]}$, but it is not considered to search the optimal rue curves.

Thus, this paper proposes the stochastic simulation model connected the GAs for searching the optimal rule curves. The synthetic inflows are used in the developed model for assessing the risk reservoir operation. The single and multi-reservoir systems are applied to assess the efficiency of the proposed technique. The proposed model is applied to determine the optimal rule curves of the Bhumibol and Sirikit Reservoirs (the Chao Phraya River Basin, Thailand) for multi-reservoir system and the Ubolratana Reservoir (the Chi River Basin, Thailand) for single system.

\section{MATERIALS AND METHODS}

\section{Genetic Algorithms embedded Stochastic Simulation Model}

The GAs connected simulation model developed in the previous study ${ }^{[12]}$ was adopted in this study. This simulation model had been constructed on the concept of HEC- $3^{[17]}$ and it can be used to simulate the reservoir operation. The reservoir operating policies are based on the rule curves of individual reservoirs and the principles of water balance concept. The reservoir system operated along the standard operating policy as expressed in Eq. (1):

$R_{v, \tau}=\left\{\begin{array}{l}D_{\tau}+W_{v, \tau}-y_{\tau}, \text { for } W_{v, \tau} \geq y_{\tau}+D_{\tau} \\ D_{\tau}, \text { for } x_{\tau} \leq W_{v, \tau}<y_{\tau}+D_{\tau} \\ D_{\tau}+W_{v, \tau}-x_{\tau}, \text { for } x_{\tau}-D_{\tau} \leq W_{v, \tau}<x_{\tau} \\ 0, \text { otherwise. }\end{array}\right.$

which $R_{v, \tau}$ is the release discharges form the reservoir during year $\nu$ and period $\tau$ ( $\tau=1$ to 12 , representing January to December); $D_{\tau}$ is the water requirement of month $\tau, x_{\tau}$ is lower rule curve of month $\tau ; y_{\tau}$ is upper rule curve of month $\tau$; and $W_{v, \tau}$ is the available water calculated by simple water balance as described in Eq.(2):

$W_{v, \tau+1}=S_{v, \tau}+Q_{v, \tau}-R_{v, \tau}-E_{\tau}-D S$

where $S_{v, \tau}$ is the stored water at the end of month $\tau ; Q_{v, \tau}$ is monthly reservoir inflow; $E_{\tau}$ is average value of evaporation loss; and $D S$ is the minimum reservoir storage capacity (the capacity of dead storage). In the Eq (1), if available water is in a range of the upper and lower rule level, then demands are satisfied in full. If available water over the top of the upper rules level, then the water is spilled from the reservoir in downstream river in order to maintain water level at upper rule level. If available water is below the lower rule level, a reduction of supply is required. The policy usually reserves the available water $\left(W_{v, \tau}\right)$ for reducing the risk of water shortage in the future, when $0 \leq$ $W_{v, \tau}<x_{\tau}-D_{\tau}$.

The results of reservoir simulation are the situations of water shortage and excess release water such as the number of failure year, the number of excess release water, and the average annual shortage. They will be then recorded for using in GAs model.

This study also uses the model of GAs technique that was developed in the previous study ${ }^{[12]}$. This GAs model requires encoding schemes that transform the decision variables (rule curves) into chromosome. Then, the genetic operations (reproduction, crossover, and mutation) are performed. This study used population size $=80$, crossover probability $=0.85$, mutation probability $=0.01$.

The objective function of searching the optimal rule curve is the average water shortage (Aver-$\mathrm{MCM} /$ year $)^{[12]}$ obtaining from the simulation model which described as follows:

$$
\text { Aver }=\frac{1}{n} \sum_{v=1}^{n} S h_{v}
$$

where $n$ is the total number of considered year and $S h_{v}$ is water deficit during year $v$.

\section{STUDY AREAS AND DATA}

The developed model was applied to search the optimal rule curve of both single reservoir system and the multi-reservoir systems. The Bhumibol and Sirikit Reservoirs located in the watershed area of the Chao Phraya River Basin (Thailand) were used to represent the multi-reservoir systems, while the Ubolratana Reservoir located in the northeast region of Thailand was illustrated the single reservoir. Figure 1 shows the locations of the Bhumibol, Sirikit and Ubolratana Reservoirs.

As shown in Fig 2, the schematic diagram of flows within the total drainage basin of the multi-reservoir systems (the Bhumibol and Sirikit reservoir). The Bhumibol Reservoir has the capacity of 13,462 MCM (million cubic meters or $10^{6} \mathrm{~m}^{3}$ ), while the Sirikit 
Reservoir has the storage of 9,510 MCM. The two reservoirs are located on the main branches (River Ping and River Nan) of the Chao Phraya River. The verification needs monthly flow records and the other related data such as monthly water requirements supplied by the reservoirs, their characteristic curves, and monthly evaporation rate. For the flow record data, two sequences of 45-year (1956-2000) monthly-flow records of stations P.12 (the Ping River) and SK (the Nan River) were used. The locations of the flow gauging stations are presented in Figure 2. There are three period types of inflow that are used in reservoir simulation including 21-year (1975-1995) covering the dry years, 45-year (1956-2000) of historic record and the 100 samples of generated inflow. The stochastic flow of stations P.12 and SK were generated by the MAR (1) ${ }^{[18]}$. The other average hydrological data for each month included series of evaporation losses and precipitation of the reservoirs, and those of side flows of stations W.4A and Y.5 were used for the search. The considered water-requirement information of the studied basin was adopted from the previous study ${ }^{[12]}$.

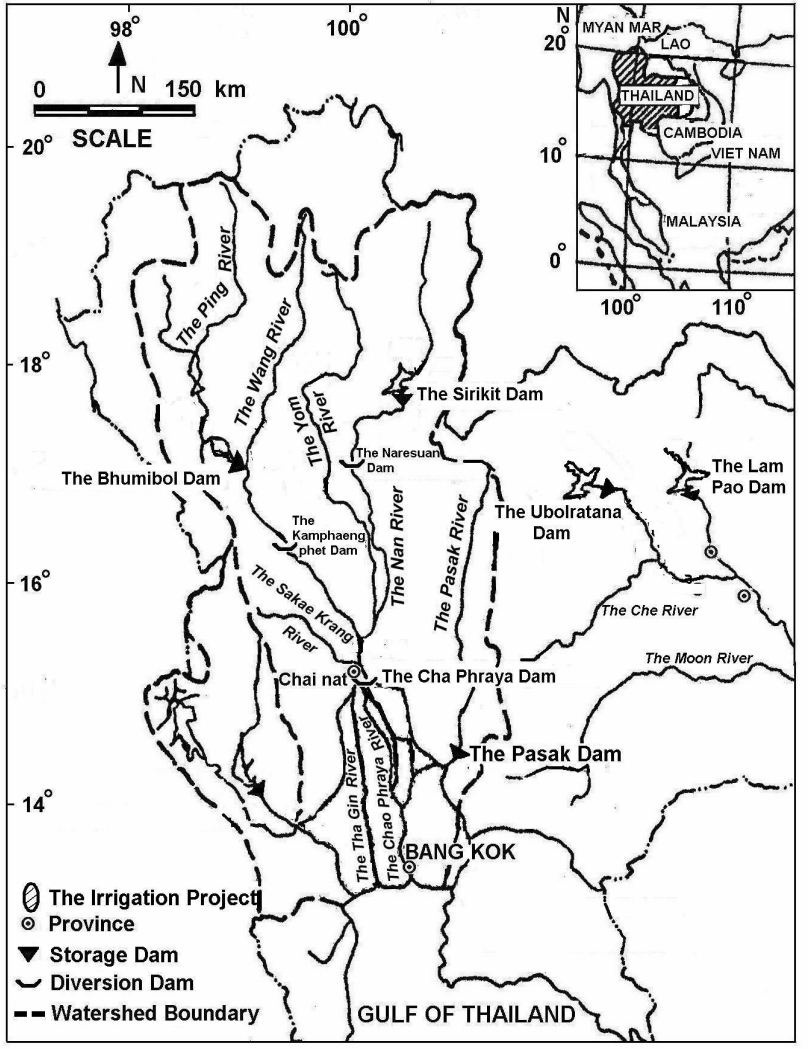

Fig. 1: Location of the Bhumibhol, Sirikit and Ubolratana Reservoirs

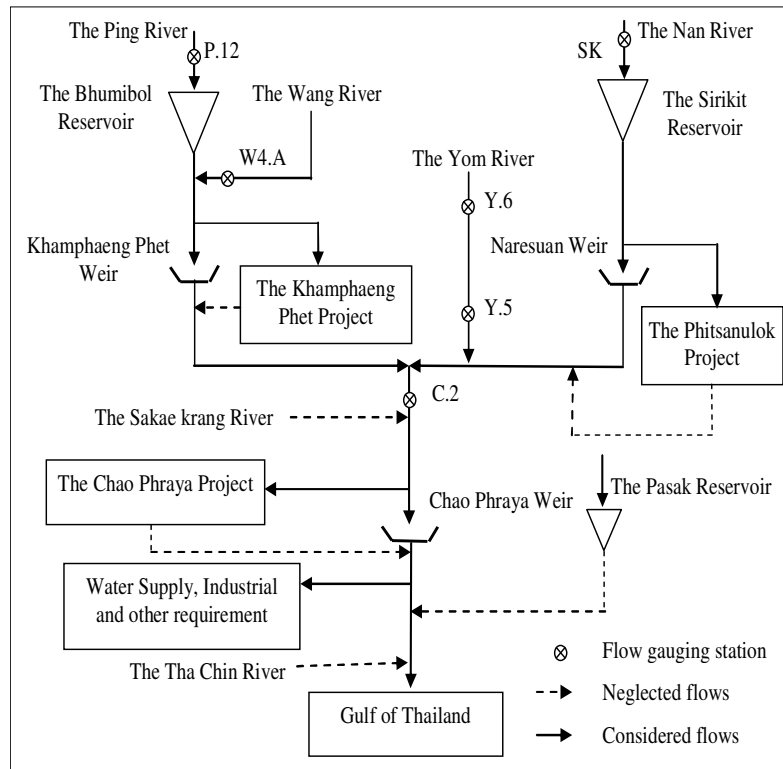

Note: The other requirements consist of salinity, pollution control and navigation demands.

Fig. 2: Schematic diagram of flows in the Chao Praya River Basin

Figure 3 shows the schematic diagram of the Ubolratana reservoir system. The Ubolratana Reservoir has the capacity of 2,263 MCM. The inflow records of station UBR (1958-2003) were considered. The inflow periods applied to simulation run include 18-year (1958-1975) covering the dry duration, 46-year (19582003) of historic record and the 100 samples of synthetic inflow. Furthermore, the other hydrological data for each month included series of evaporation losses and precipitation of the reservoirs, and those of side flows were used for reservoir simulation.

The model results of all three periods obtained from applying the optimal rule curves to the Monte Carlo simulation were compared to the situations of water shortage and excess release (e.g., frequency, magnitude, and duration). The Monte Carlo simulation study against 500 samples of generated monthly flows for stations P.12 and $\mathrm{SK}^{[18]}$ was used to compute the interval (mean \pm standard deviation) of the referred statistics for the assessment.

For the single system, the optimal rule curves were used to assess by the comparing the situations of water deficit and excess release for the mentioned three periods. The 500 samples of generated monthly flows of station UBR were used to calculate the referred situations by the Monte Carlo simulation for the assessment. In the following, the obtained assessment results of the considered water- deficit and excessrelease properties for all cases were presented. 


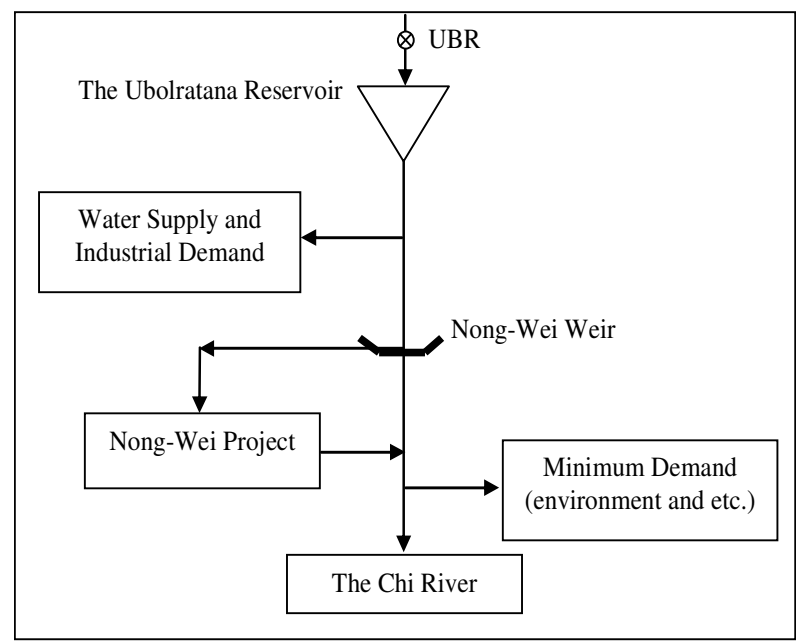

Fig. 3: Schematic diagram of flows in the Chi River Basin

\section{RESULTS AND DISCUSSIONS}

The multi-reservoir system: Figures 4 and 5 show the optimal rule curves of the Bhumibol and Sirikit Reservoirs for three periods of inflow respectively. The patterns of the rule curves for both reservoirs are good in agreement with respect to the seasonality effects on reservoir inflows and considered water demands. The optimal rule curves using different periods of searching are not explicitly different. These optimal rule curves were then evaluated to examine the water situations by the Monte Carlo simulation study with 500 samples of generated flow samples.

Tables 1 and 2 show the assessment intervals of water shortage and excess release characteristics for all types of inflow records respectively. The results of water situations are not significantly different among all inflow record type. However, the frequency, magnitude and duration of water shortage for the synthetic inflow are smaller than those of the other periods but not for maximum magnitude. As shown in Fig 2, the maximum magnitude of excess release using stochastic inflow yield the smallest volume of 4,451 $\pm 1,819 \mathrm{MCM} /$ year. Therefore, the developed model using synthetic inflows provides the optimal rule curves that highly alleviate the situations of water shortage and excess release. It is concluded that the stochastic simulation model embedded GAs technique provides the optimal rule curves since it considers the risk of reservoir operation caused by the uncertainty of natural inflow for multireservoir system.

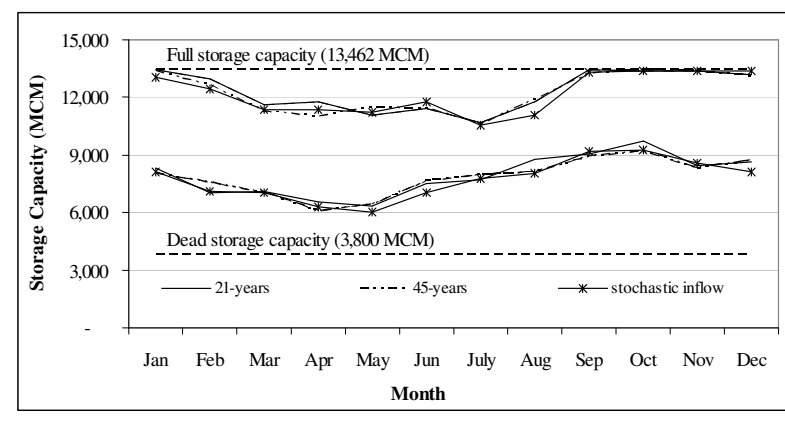

Fig. 4: Optimal rule curves of the Bhumibol Reservoir (multi-reservoir system)

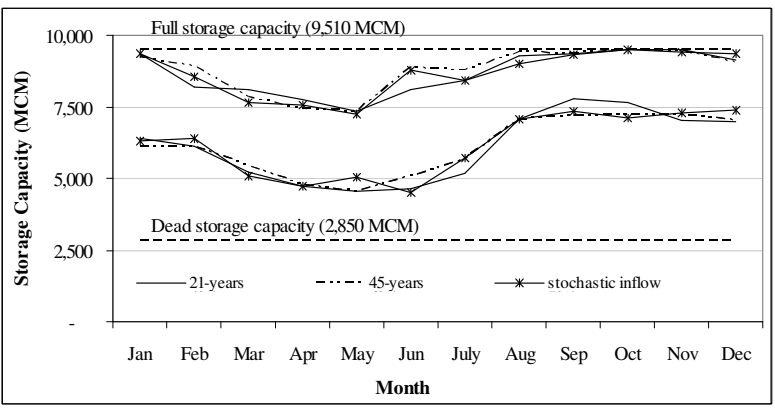

Fig. 5: Optimal rule curves of the Sirikit Reservoir (multi-reservoir system)

\section{The single-reservoir system}

Figure 6 shows the optimal rule curves of the Ubbolratanat Reservoirs using the three durations of inflow for searching. The patterns of the rule curves of three cases are in good agreement with respect to the seasonality effects on reservoir inflows and considered water demands. The optimal rule curves using the different period of inflow are not explicitly different. These optimal rule curves were then evaluated to examine the situations of water shortage and excess release by the Monte Carlo simulation study using 500 samples of generated inflow of station UBR.

Tables 3 and 4 show the assessment intervals of water shortage and excess release characteristics for all durations of inflow records respectively. They indicate that the interval of water deficit and excess release of rule curves using all periods are not significantly different. However, the most intervals of the rule curves using synthetic inflow are slightly smaller than those using the other inflow types. This implies that the synthetic inflow in stochastic simulation could handle the risk of reservoir operation in the case of single reservoir system. 
Am. J. Applied Sci., 5 (3): 221-226, 2008

Table 1: Frequency, magnitude and duration of water shortage for all inflow record types (multi-reservoir system)

\begin{tabular}{|c|c|c|c|c|c|c|}
\hline \multirow{2}{*}{\multicolumn{2}{|c|}{ Inflow record type }} & \multirow{2}{*}{$\begin{array}{l}\text { Frequency } \\
\text { (times/year) }\end{array}$} & \multicolumn{2}{|c|}{ Magnitude (MCM/year) } & \multicolumn{2}{|c|}{ Duration (year) } \\
\hline & & & Average & Maximum & Average & Maximum \\
\hline \multirow{2}{*}{ 21-year } & $\mu$ & 0.137 & 24 & 323 & 2.0 & 3.1 \\
\hline & $\sigma$ & 0.076 & 18 & 206 & 1.0 & 1.7 \\
\hline \multirow{2}{*}{ 45-year } & $\mu$ & 0.113 & 19 & 289 & 1.9 & 2.7 \\
\hline & $\sigma$ & 0.070 & 16 & 219 & 0.9 & 1.6 \\
\hline \multirow{2}{*}{$\begin{array}{l}\text { Stochastic } \\
\text { inflow }\end{array}$} & $\mu$ & 0.104 & 18 & 300 & 1.8 & 2.6 \\
\hline & $\sigma$ & 0.068 & 17 & 253 & 1.0 & 1.6 \\
\hline
\end{tabular}

Note: $\mu=$ mean, $\sigma=$ standard deviation

Table 2: Frequency, magnitude and duration of excess release for all inflow record types (multi-reservoir system)

\begin{tabular}{ccccccc}
\hline \multirow{2}{*}{ Inflow record type } & $\begin{array}{c}\text { Frequency } \\
\text { (times/year) }\end{array}$ & \multicolumn{2}{c}{ Magnitude (MCM/year) } & \multicolumn{2}{c}{ Duration (year) } \\
& & Average & Maximum & Average & Maximum \\
\hline \multirow{2}{*}{ 21-year } & $\mu$ & 0.816 & 1,108 & 4,545 & 7.2 & 15.3 \\
& $\sigma$ & 0.079 & 198 & 1,862 & 3.3 & 5.9 \\
45-year & $\mu$ & 0.811 & 1,110 & 4,706 & 7.0 & 15.0 \\
& $\sigma$ & 0.079 & 202 & 1,905 & 3.1 & 5.6 \\
Stochastic & $\mu$ & 0.815 & 1,139 & 4,451 & 7.2 & 15.4 \\
inflow & $\sigma$ & 0.080 & 203 & 1,819 & 3.3 & 5.8 \\
\hline
\end{tabular}

Note: $\mu=$ mean, $\sigma=$ standard deviation

Table 3: Frequency, magnitude and duration of water shortage for all inflow record types (single-reservoir system)

\begin{tabular}{ccccccc}
\hline \multirow{2}{*}{ Inflow record type } & $\begin{array}{c}\text { Frequency } \\
\text { (times/year) }\end{array}$ & \multicolumn{2}{c}{ Magnitude (MCM/year) } & \multicolumn{2}{c}{ Duration (year) } \\
& & Average & Maximum & Average & Maximum \\
\hline \multirow{2}{*}{ 18-year } & $\mu$ & 0.674 & 108 & 490 & 3.1 & 8.2 \\
& $\sigma$ & 0.048 & 11 & 151 & 0.7 & 2.9 \\
46-year & $\mu$ & 0.821 & 157 & 438 & 5.3 & 13.2 \\
& $\sigma$ & 0.036 & 9 & 127 & 1.5 & 5.3 \\
Stochastic & $\mu$ & 0.661 & 97 & 468 & 3.1 & 8.15 \\
inflow & $\sigma$ & 0.047 & 11 & 139 & 0.7 & 2.7 \\
\hline
\end{tabular}

Note: $\mu=$ mean, $\sigma=$ standard deviation

Table 4: Frequency, magnitude and duration of excess release for all inflow record types (single-reservoir system)

\begin{tabular}{ccccccc}
\hline \multirow{2}{*}{ Inflow record type } & $\begin{array}{c}\text { Frequency } \\
\text { (times/year) }\end{array}$ & \multicolumn{2}{c}{ Magnitude (MCM/year) } & \multicolumn{2}{c}{ Duration (year) } \\
& & Average & Maximum & Average & Maximum \\
\hline \multirow{2}{*}{ 18-year } & $\mu$ & 0.904 & 988 & 3,278 & 10.3 & 19.5 \\
& $\sigma$ & 0.036 & 21 & 618 & 4.1 & 6.9 \\
46-year & $\mu$ & 0.920 & 1032 & 3,310 & 12.4 & 22.6 \\
& $\sigma$ & 0.035 & 19 & 621 & 6.4 & 7.9 \\
Stochastic & $\mu$ & 0.898 & 975 & 3,230 & 9.9 & 19.1 \\
inflow & $\sigma$ & 0.035 & 21 & 597 & 3.9 & 6.7 \\
\hline
\end{tabular}

Note: $\mu=$ mean, $\sigma=$ standard deviation 


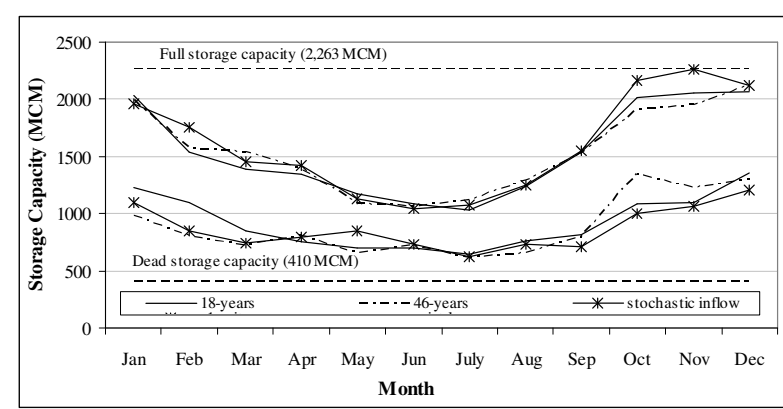

Fig. 6: Optimal rule curves of the Ubolratana Reservoir (single reservoir system)

\section{CONCLUSION}

This study developed stochastic simulation model embedded genetic algorithm model for searching the optimal rule curves. The synthetic inflows were applied to the proposed model for concerning the risk of reservoir operation caused by natural uncertainty from inflow. The developed model was assessed for both single and multi-reservoir systems. The results presented that the obtained rule curves using the historic inflow record in both cases of single and multireservoir systems are similar.

The optimal rule curves of each system were also used to assess the situation of water deficit and excess release by a Monte Carlo simulation with the 500 samples of generated inflow. The results showed that the situations of water shortage and excess release in this study are not significantly different from those obtained by tradition simulation. The stochastic simulation model connected genetic algorithm provided the optimal rule curves as considering the risk of reservoir operation. Furthermore, the proposed model is applicable for both single and multi-reservoir systems.

\section{ACKNOWLEDGEMENTS}

We authors would like to express their appreciation to the Faculty of Engineering, Mahasarakham University for financial support and Miss Sudarat Compliew for helpful calculation the synthetic flows.

\section{REFERENCES}

1. Jain, K.S., K.M. Goel and K.P. Agarwal, 1998. Reservoir operation study of sabamati system, India. J. Water Res. Plan. Manag., 124: 31-38.

2. Xu, Z. X. and K. Ito, 1997. Incorating inflow uncertainty into risk assessment for reservoir operation. Stochastic Hydrology and Hydraulics,. 11: 433-448.

3. Tilmant, A., P. Fortemps and M. Vanclooster, 2002. Effect of averaging operators fuzzy optimization of reservoir operation. Water Resources Management, 16: 1-22.
4. Bellman, R., 1959. Dynamic Programming. Princetion University Press, Princeton, New Jersey.

5. Yakowitz, S., 1982. Dynamic programming applications in water resource. Water Resources Res., 18: 673-696.

6. Esogbue, O.A., 1989. Dynamic Programming for Optimal Water Resources Systems Analysis. Prentice Hall, Englewood Cliffs, New Jersey.

7. Chaleeraktrakoon, C. and A. Kangrang, 2007. Dynamic Programming with The Principle of Progressive Optimality for Searching Rule Curves", Canadian Journal of Civil Engineering, 34 (2): 170-176.

8. Chang, C.L. and C.C. Yang, 2002. Optimizing the rule curves for multi-reservoir operations using a genetic algorithm and HEC-5. J. Hydroscience and Hydraulic Eng., 20: 59-75.

9. Chang, J.F., S.J. Lai and S.L. Kao, 2003. Optimization of operation rule curves and flushing schedule in a reservoir. Hydrological Processes, 17: 1623-1640.

10. Chen, L., 2003. Real coded genetic algorithm optimization of long term reservoir operation. J. Am. Water Res. Assoc., 39: 1157-1165.

11. Chang, J.F., L. Chen and C.L. Chang, 2005. Optimizing reservoir operating rule curves by genetic algorithms. Hydrological Processes, 19: 2277-2289.

12. Kangrang, A. and C. Chaleeraktrakoon, 2007. Genetic algorithms connected simulation with smoothing function for searching rule curves. Am. J. Applied Sci, 4 (2): 73-79.

13. Tatano, H., N. Okada and H. Kawai, 1992. Optimization model of a single reservoir with drought duration explicitly concerned. Stochastic Hydrology Hydraulics, 6: 123-134.

14. Meigh, J. R. and N. S. Reynard, 2005. Probabilistic 8-Day rainfall estimates for The Sanaga Basin, Cameroon. Water Resources Management, 9: 6780.

15. Tospornsampan, J., I. Kita, M. Ishii and Y. Kitamra, 2005. Optimization of multiple reservoir system using a simulated annealing-A case study in The Mae Klong System, Thailand. Paddy Water Environ, 3: 1337-1347.

16. Simonovic, S. P., H. D. Venema and D. H. Burn, 1992. Risk-based parameters selection for shortterm reservoir operation. Journal of Hydrology, 131, 269-291.

17. US Army Corp. of Hydrologic Engineering Center (HEC-3), 1974. HEC-3 Reservoir System Analysis for Conservation. User's Manual, California, U.S.A.

18. Chaleeraktrakoon, C., 1999. Stochastic procedure for generating seasonal flows. J. Hydrologic Engineer, ASCE, 4: 337-343. 